\title{
Identification of a novel mutation in the autoimmune regulator (AIRE-1) gene in a French family with autoimmune polyendocrinopathy-candidiasis-ectodermal dystrophy
}

\author{
P Saugier-Veber, N Drouot, L M Wolf ${ }^{1}$, J M Kuhn ${ }^{1}$, T Frébourg and H Lefebvre ${ }^{1}$ \\ Laboratory of Molecular Genetics, INSERM EMI 9906, University of Rouen, Rouen, France, and ${ }^{1}$ Department of Endocrinology and Metabolic Diseases, \\ INSERM U 413, University Hospital of Rouen, European Institute for Peptide Research \\ (IFRMP no. 23), Rouen, France \\ (Correspondence should be addressed to P Saugier-Veber, INSERM EPI 9906, Faculté de Médecine et de Pharmacie, 22 boulevard Gambetta, \\ 76183 Rouen, France; Email: Pascale.Saugier-Veber@chu-rouen.fr)
}

\begin{abstract}
Autoimmune polyendocrinopathy-candidiasis-ectodermal dystrophy (APECED) is clinically characterized by the presence of two of the three major clinical symptoms: Addison's disease and/or hypoparathyroidism and/or chronic mucocutaneous candidiasis. Because of its autosomal recessive inheritance, this rare disorder constitutes an interesting model for understanding the molecular background of autoimmunity. Recently, mutations in the autoimmune regulator (AIRE-1) gene have been identified in APECED patients. Here we report, in a large French APECED family, the identification of a novel AIRE-1 missense mutation (Pro326Leu) in association with the Arg257Stop mutation which is detected in more than $80 \%$ of mutant Finnish AIRE-1 alleles. This Pro326Leu substitution occurs in the first plant homeodomain (PHD)-type zinc-finger domain of the protein which has been identified in a number of nuclear proteins involved in chromatin-mediated transcriptional regulation, such as ATRX, TIF1, KRIP-1 and Mi-2 autoantigen. This mutation highlights the key role of this amino acid in the structure of the PHD domain and confirms that exon 8 constitutes a mutational hotspot.
\end{abstract}

European Journal of Endocrinology $144347-351$

\section{Introduction}

Autoimmune polyendocrinopathy-candidiasis-ectodermal dystrophy (APECED) is an autosomal recessive disease characterized by the association of hypoparathyroidism, primary adrenocortical failure and chronic mucocutaneous candidiasis (1). The clinical phenotype of APECED is highly variable, including the failure of parathyroid glands, adrenal cortex, gonads, pancreatic $\beta$-cells, and gastric parietal cells, resulting from autoimmune reactions towards endocrine and nonendocrine organs (2). Since APECED is the only systemic human autoimmune disease inherited in a Mendelian fashion, it provides an excellent model to analyse the genetic basis of human autoimmunity (3).

In most populations, APECED is a rare disorder. However, the incidence has been estimated to be $1 / 25000$ in Finland and 1/9000 in Iranian Jews because of founder effects $(1,4)$. The founder effect in Finnish APECED families has allowed the genetic mapping by linkage analysis to a $2.6 \mathrm{cM}$ region on chromosome 21q22.3 (5). Subsequently, the autoimmune regulator gene (AIRE-1) was identified and 29 different AIRE-1 mutations have already been found in APECED families (6-15). One particular nonsense mutation, Arg257Stop, was found to account for $89 \%$ of mutant Finnish AIRE-1 alleles (15).

We report the identification of the two mutations in the AIRE-1 gene, including a novel mutation, in a large French APECED family.

\section{Patients and methods}

\section{Patients}

This French APECED family is descended from healthy, non-consanguineous parents and comprises eleven children, three of whom are affected with APECED. The oldest sibling (patient $\mathrm{II}_{1}$; Fig. 1) is now 48 years old. She presented no symptom of candidiasis or adrenocortical failure during infancy. At 29 years old, she presented with tetany secondary to hypocalcemia. Hypoparathyroidism was documented and the patient was successfully treated with 1-hydroxyvitamin D3. Recent physical examination did not show any other 


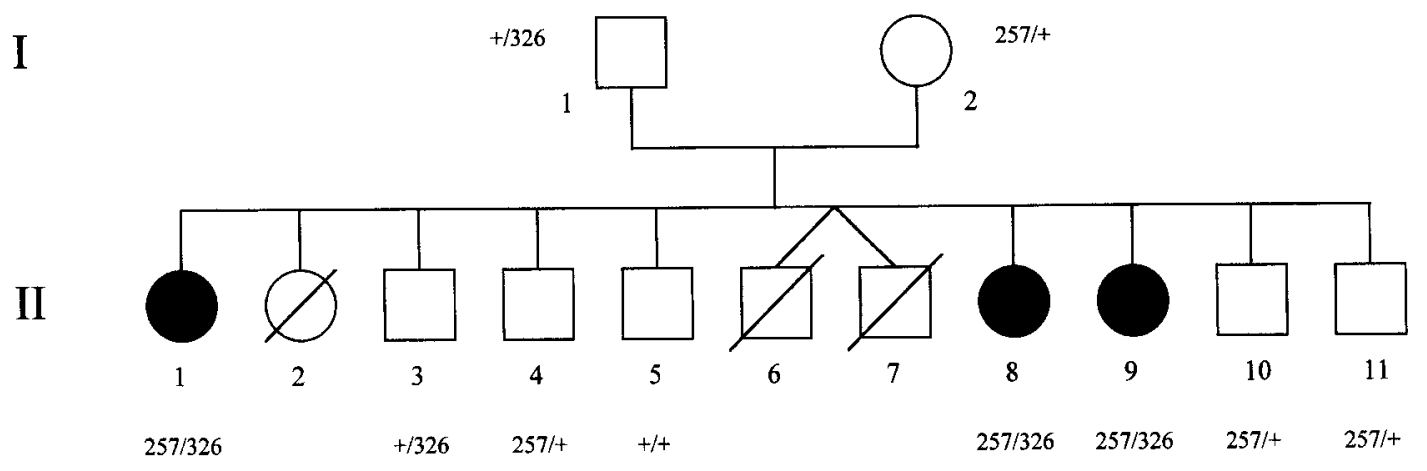

Figure 1 Pedigree of the APECED family. Segregation of the Arg257Stop and Pro326Leu mutations is presented. $+/+$, wild-type genotype; 257/+, heterozygous Arg257Stop mutation; +/326, heterozygous Pro326Leu mutation; 257/326, Arg257Stop and Pro326Leu compound heterozygote. Squares, males; circles, females; solid symbols, affected subjects; open symbols, asymptomatic individuals; slash, subject deceased.

sign of ectodermal dystrophy or endocrine dysfunction. Hormone assays, including basal hormone level determinations and dynamic tests, revealed that adrenocortical, ovarian and pituitary functions were normal as well as fasting glycemia and liver enzymes. In addition, antibodies against endocrine glands, gastric parietal cells and intrinsic factor were not detected.

Sibling $\mathrm{II}_{2}$ died at 5 years old of leukemia and subjects $\mathrm{II}_{6}$ and $\mathrm{II}_{7}$ died at 3 weeks of sudden infant death syndrome.

Patient $\mathrm{II}_{8}$ was hospitalized at the age of 3 years for epileptic crisis and treatment with phenobarbital was started. However, epileptic manifestations were poorly controlled by the treatment and the patient was rehospitalized at the age of 6 years. Blood assays revealed profound hypocalcemia consecutive to hypoparathyroidism and she was treated with calcium gluconate and 1-hydroxyvitamin D3. Enamel hypoplasia was observed at the age of 14 years. Puberty occurred at the age of 15 years. Pernicious anemia was diagnosed at the age of 18 years after the patient complained of fatigue. Parenteral treatment with vitamin B12 normalized blood red cell count and mean corpuscular volume. Oral and vaginal candidiasis were observed at the age of 21 years. Primary ovarian failure, revealed by amenorrhea associated with high plasma levels of follicle-stimulating hormone, occurred at 22 years of age and estrogen-progestogen treatment was started. The patient is now 35 years old and has no clinical or biological sign of additional endocrine deficits.

Sibling $\mathrm{II}_{9}$ presented with tetany consecutive to hypocalcemia at 4 years of age. Hypoparathyroidism was documented and calcemia was normalized after treatment with calcium gluconate and 1-hydroxyvitamin D3. At the age of 12 years, the patient was hospitalized for dehydratation and fever. Plasma electrolyte assays revealed hyponatremia and hypercalcemia. She improved dramatically after parenteral administration of hydrocortisone. Primary adrenocortical insufficiency was confirmed by hormone assays showing low levels of cortisol and high levels of corticotropin. Long-term replacement treatment with hydrocortisone $(30 \mathrm{mg} /$ day) and fluorohydrocortisone (50 $\mu \mathrm{g} /$ day) was maintained. Two years later, despite hormone and vitamin D3 replacement, growth retardation was evident and no sign of pubertal development was observed. Primary ovarian failure was then documented. Estrogen-progestogen combination was administered and led to an acceleration of growth and normal feminization. At the age of 26 years, mild intermittent elevation of liver enzymes (around twice the upper limit of normal for maximum aspartate aminotransferase and alanine aminotransferase values) was observed. Liver biopsy revealed chronic hepatitis with histological features characteristic of viral infection. Hepatitis viral serology was positive for hepatitis C. Liver enzymes normalized spontaneously and no antiviral treatment was administered. Pernicious anemia was diagnosed at 33 years of age and treatment with parenteral vitamin B12 was started. The patient is now 33.5 years old and has no clinical or biological sign of ectodermal dystrophy, pituitary dysfunction or diabetes. Liver enzymes remain normal without any treatment.

Siblings $\mathrm{II}_{3}, \mathrm{II}_{4}, \mathrm{II}_{5}, \mathrm{II}_{10}$ and $\mathrm{II}_{11}$ were systematically screened for endocrine failures, ectodermal dystrophy, candidiasis, hepatitis and biological signs of autoimmunity. Clinical examination and biological tests were normal in all cases.

\section{DNA extraction and sequence analysis}

Genomic DNA was extracted from blood samples using the Qiagen blood and cell culture DNA kit (Qiagen, Courtaboeuf, France). The 14 exons of the AIRE-1 gene were PCR-amplified using intronic primers described by Pearce et al. (9). PCR reactions were performed in a final volume of $50 \mu \mathrm{l}$ containing $0.5 \mu \mathrm{mol} / \mathrm{l}$ of each primer and 1 U Taq DNA polymerase (Eurobio, Les Ulis, France). The PCR consisted of 35 cycles of $15 \mathrm{~s}$ at 
$94{ }^{\circ} \mathrm{C}, 15 \mathrm{~s}$ at $59-65{ }^{\circ} \mathrm{C}$ and $20 \mathrm{~s}$ at $72{ }^{\circ} \mathrm{C}$, preceded by $3 \mathrm{~min}$ at $95{ }^{\circ} \mathrm{C}$ and followed by $5 \mathrm{~min}$ at $72{ }^{\circ} \mathrm{C}$. PCR products were purified using the Qiaquick gel extraction kit (Qiagen) after electrophoresis on a 2\% Nusieve GTG agarose (FMC, Rockland, ME, USA) gel. Sequencing reactions were performed using rhodamine dye terminator sequencing kits (Applied Biosystems, Perkin Elmer-Cetus, Courtaboeuf, France) and sequences were analyzed on an ABI 377 automated DNA sequencer (Applied Biosystems, Perkin Elmer-Cetus).

\section{Screening for the Pro326Leu mutation}

Screening for the Pro326Leu mutation was performed on genomic DNA by restriction fragment analysis since this mutation abolishes a BsrBI restriction site. A 229 bp fragment was PCR-amplified using the AIRE-8F and AIRE-8R primers (9) and one-fifth of the PCR reaction $(10 \mu \mathrm{l})$ was digested with $2.5 \mathrm{U}$ BsrBI restriction enzyme (New England Biolabs) in a final volume of $50 \mu \mathrm{l}$ overnight at $37^{\circ} \mathrm{C}$. The resulting fragments were resolved on a 3\% LE GTG Agarose (FMC) gel (Fig. 2).

\section{Screening for the Arg257Stop mutation}

Since the Arg257Stop mutation generates a TaqI restriction site, screening for the Arg257Stop mutation was performed by PCR-amplification of exon 6 with the AIRE-6F and AIRE-6R primers (9) followed by restriction digestion with TaqI (New England Biolabs). Onefifth of the PCR reaction $(10 \mu \mathrm{l})$ was digested with $5 \mathrm{U}$ TaqI for $5 \mathrm{~h}$ at $65{ }^{\circ} \mathrm{C}$ in a final volume of $50 \mu \mathrm{l}$. The resulting fragments were resolved on a 3\% LE GTG agarose (FMC) gel (Fig. 2).

\section{Results}

In non-Finnish patients with APECED, the most common mutation within the AIRE-1 gene was shown to be the 1085-1097del in exon 8 followed by the Arg257Stop in exon $6(9,12)$. The existence of these recurrent mutations prompted us to sequence first these two exons in an affected subject of this French APECED family ( $\mathrm{II}_{9}$; Fig. 1). We identified in exon 6 a $\mathrm{C}$ to $\mathrm{T}$ transition (nucleotide 889; Fig. 2) that converted the arginine at codon 257 into a stop codon (CGA $\rightarrow$ TGA; Arg257Stop) and a second C to $\mathrm{T}$ transition in exon 8 of the gene (nucleotide 1097; Fig. 2) resulting in a proline to a leucine substitution in the zinc-finger domain of the AIRE-1 protein $(\mathrm{CCG} \rightarrow$ CTG; Pro326Leu). In addition to these two mutations, sequencing of the entire coding region revealed two silent heterozygous mutations: a $\mathrm{T}$ to $\mathrm{C}$ transition in exon 5 (nucleotide 708; Ser196Ser), already described as a polymorphism (9) and another $\mathrm{T}$ to $\mathrm{C}$ transition in exon 10 (nucleotide 1317; Ala399Ala). The Arg257Stop and Pro326Leu mutations cosegregated with the disease within this family
(Figs 1 and 2). The Arg257Stop mutation was inherited from the mother of $\mathrm{II}_{9}$, whereas the Pro326Leu mutation was inherited from her father. The Pro326Leu mutation was not detected in 100 control chromosomes, indicating that this mutation did not correspond to a polymorphism.

\section{Discussion}

Recently, the gene responsible for APECED was identified on chromosome 21q22.3 and called AIRE-1 for autoimmune regulator gene $(6,7)$. The AIRE-1 protein contains a newly characterized domain named SAND which is suspected to function as a DNA-binding domain (16) and two plant homeodomain (PHD)-type zinc-finger motifs (3) suggesting macromolecule-binding properties. AIRE-1 expression is restricted to particular cells in thymus medulla, in lymph node paracortex and medulla and in spleen and fetal liver, but not in target organs of autoimmune destruction (17). Its pattern of expression and its localization in nuclear structures suggest its involvement in the regulation of gene expression in the pathways of induction and maintenance of immune tolerance $(18,19)$. Recently, evidence of its role in transcription regulation has been suggested in transactivation assays using a fusion protein with Gal4 DNAbinding domain and APECED, and a luciferase reporter gene (15).

In this study, we report the identification of a novel AIRE-1 missense mutation (Pro326Leu) in a French APECED family in association with the Arg257Stop mutation which is detected in $89 \%$ of mutant Finnish AIRE-1 alleles $(6,15)$. Several observations indicate that the Pro326Leu substitution, located in exon 8 , is likely pathogenic. (i) This mutation, which is predicted to produce a drastic change in the conformation of the protein, occurs in the first PHD-type zinc-finger domain of the protein. This structural motif has been identified in a number of nuclear proteins involved in chromatinmediated transcriptional regulation, such as ATRX (20), TIF1 (21), KRIP-1 (22) and Mi-2 autoantigen (23). Therefore, it is possible that the Pro326Leu mutation might alter the DNA-binding function of AIRE-1 protein. (ii) Recently, a Finnish patient has been found to be homozygous for another mutation affecting the same amino acid (Pro326Gln) providing evidence of the key role of this amino acid in the first PHD finger (15). (iii) Sequencing of the entire coding region of the proband revealed no other mutation but only two silent heterozygous mutations in exons 5 and 10, which may correspond to polymorphisms. (iv) The Arg257Stop and Pro326Leu mutations cosegregated with the disease within the APECED family (Figs 1 and 2). (v) The Pro326Leu mutation was not found in 100 control chromosomes, indicating that this variation is not a common polymorphism. Finally, the identification of a novel mutation in exon 8 confirms that this exon constitutes a mutational hot spot (15). 
a

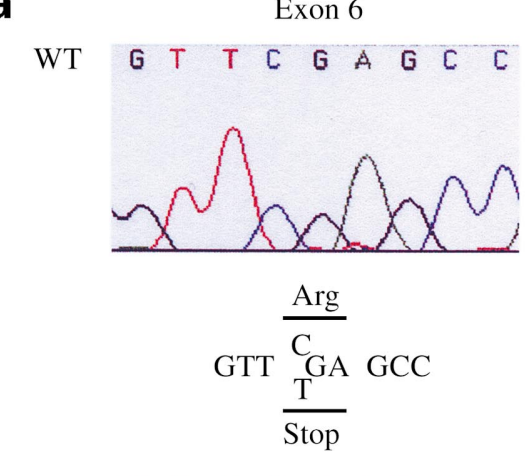

b

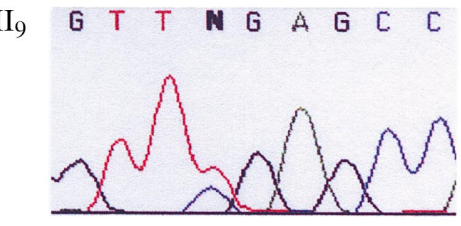

Exon 8

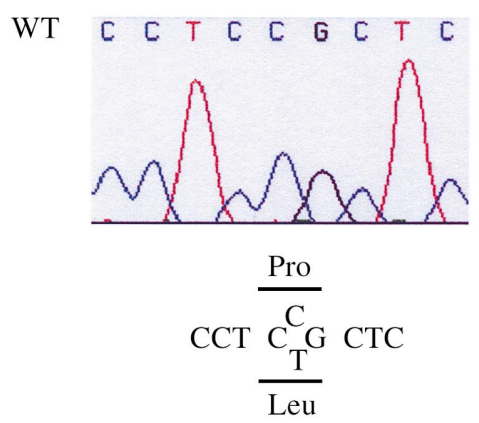

$\mathrm{II}_{9} \quad C \quad C \quad C \quad T \quad C \quad N \quad$ N

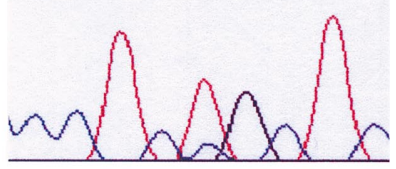

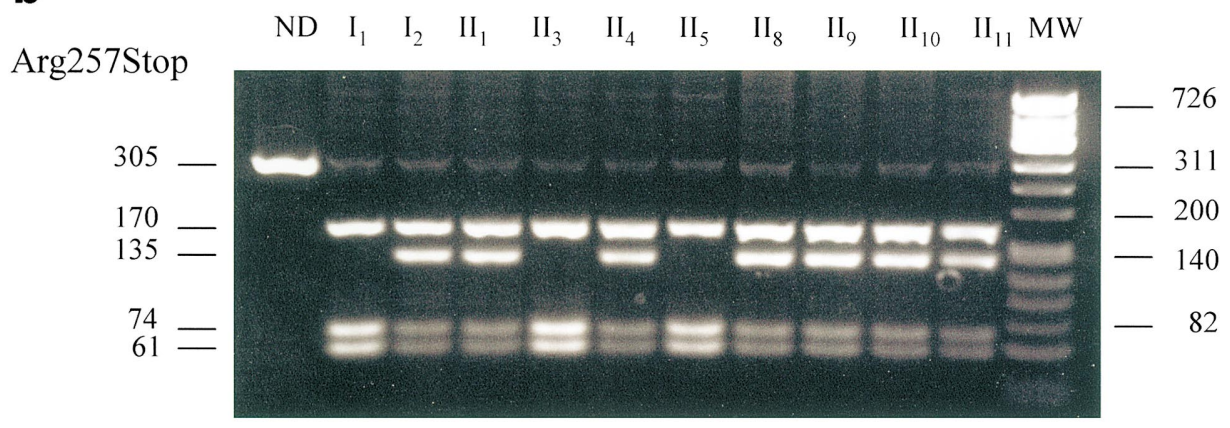

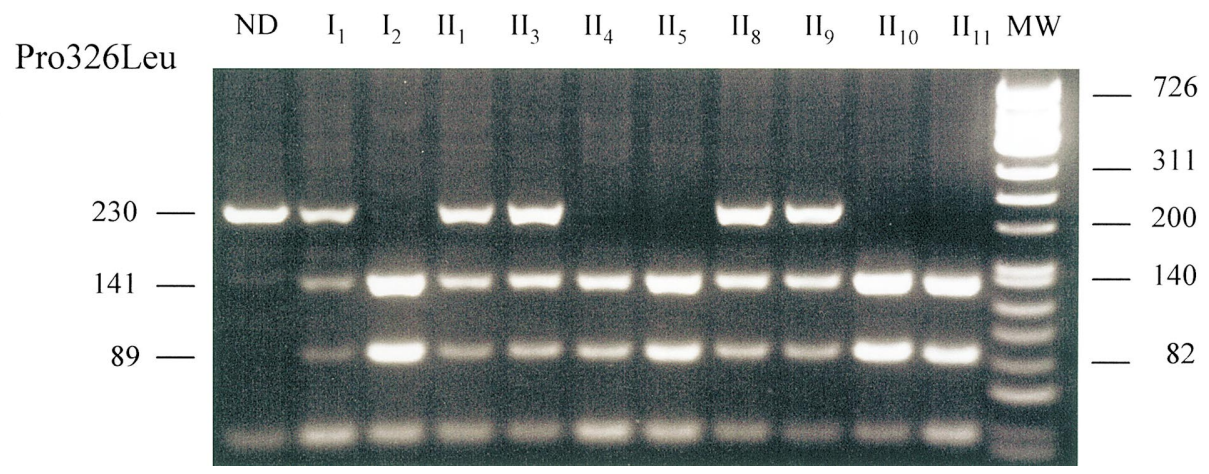

Figure 2 Detection of the AIRE-1 mutations in a French APECED family. (a) Identification of the mutations by sequencing analysis. Patient $I_{9}$ is heterozygous for a $C$ to $T$ transition (exon 6) which creates a stop codon at codon 257 and for a $C$ to $T$ transition of the cDNA (exon 8) which converts a proline into a leucine at codon 326 of the protein. (b) Segregation of the Arg257Stop and Pro326Leu mutations within the family. The presence of the mutation Pro326Leu was demonstrated by restriction digestion analysis with BsrBI whereas the presence of the Arg257Stop mutation was demonstrated by digestion with Taql. Fragment sizes (in bp) of the molecular weight marker (Hinf I-digested $\Phi$ X174) are shown to the right of the gels. Undigested PCR products are loaded on the left of the gels (ND, not digested). Because of the existence of an internal natural Taql restriction site, the wild-type (WT) allele generates two restriction fragments of 170 and 135 bp whereas the mutant allele containing the Arg257Stop mutation generates three restriction fragments of 170, 74 and $61 \mathrm{bp}$. The mutant allele containing the Pro326Leu mutation generates a $230 \mathrm{bp}$ PCR product undigested after BsrBI digestion whereas the wild-type product generates two restriction fragments of 141 and $89 \mathrm{bp}$. 
The exact function of AIRE-1 is still unknown. The PHD-type zinc-finger domains present strong sequence homology with Mi-2 PHD-type zinc-finger motifs. Mi-2, which constitutes the major autoantigen in dermatomyositis patients, is a component of a protein complex containing histone deacetylase and nucleosome remodeling activities which are involved in regulation of gene expression by way of DNA methylation (24-26). AIRE-1 homology with Mi-2 might suggest that AIRE-1 could also be involved in nucleosome remodeling activities for the regulation of gene expression in the pathways of induction and maintenance of immune tolerance.

In agreement with previous reports of APECED families $(10,14)$, our observation shows that the clinical presentation of the disease is highly variable within a single pedigree. In particular, some patients may present with only one symptom while others present with multiple endocrine deficits, candidiasis, hepatitis and ectodermal dystrophy, illustrating the lack of correlation between phenotype and genotype in APECED. This case report also highlights the importance of familial investigation even when only one of the diagnosis criteria of APECED is present in a patient. In this regard, the identification of AIRE-1 mutations will facilitate the confirmation of APECED diagnosis in the index case and presymptomatic diagnosis within the family.

\section{References}

1 Ahonen P. Autoimmune polyendocrinopathy-candidosis-ectodermal dystrophy (APECED): autosomal recessive inheritance. Clinical Genetics 198527 535-542.

2 Ahonen P, Myllärniemi S, Sipilä I \& Perheentupa J. Clinical variation of autoimmune polyendocrinopathy-candidiasis-ectodermal dystrophy (APECED) in a series of 68 patients. New England Journal of Medicine 1990322 1829-1836.

3 Björses P, Aaltonen J, Horelli-Kuitunen N, Yaspo ML \& Peltonen L. Gene defect behind APECED: a new clue to autoimmunity. Human Molecular Genetics 19987 1547-1553.

4 Zlotogora J \& Shapiro MS. Polyglandular autoimmune syndrome type I among Iranian Jews. Journal of Medical Genetics 199229 $824-826$.

5 Aaltonen J, Björses P, Sandkuijl L, Perheentupa J \& Peltonen L. An autosomal locus causing autoimmune disease: autoimmune polyglandular disease type I assigned to chromosome 21 . Nature Genetics 19948 83-87.

6 The Finnish-German APECED consortium (Group 1: Aaltonen J, Björses P, Perheentupa J, Horelli-Kuitunen N, Palotie A \& Peltonen L; Group 2: Lee LS, Francis F, Hennig S, Thiel C, Lehrach H \& Yaspo ML). An autoimmune disease, APECED, caused by mutations in a novel gene featuring two PHD-type zinc-finger domains. Nature Genetics 199717 399-403.

7 Nagamine K, Peterson P, Scott HS, Kudoh J, Minoshima S, Heino $\mathrm{M}$ et al. Positional cloning of the APECED gene. Nature Genetics 199717 393-398.

8 Scott HS, Heino M, Peterson P, Mittaz L, Lalioti MD, Betterle C et al. Common mutations in autoimmune polyendocrinopathycandidiasis-ectodermal dystrophy patients of different origins. Molecular Endocrinology 199812 1112-1119.

9 Pearce SH, Cheetham T, Imrie H, Vaidya B, Barnes ND, Bilous RW et al. A common and recurrent 13-bp deletion in the autoimmune regulator gene in British kindreds with autoimmune polyendocrinopathy type I. American Journal of Human Genetics 199863 1675-1684.

10 Myhre AG, Björses P, Dalen A \& Husebye ES. Three sisters with Addison's disease. Journal of Clinical Endocrinology and Metabolism 199883 4204-4206.

11 Rosatelli MC, Meloni A, Devoto M, Cao A, Scott HS, Peterson P et al. A common mutation in Sardinian autoimmune polyendocrinopathy-candidiasis-ectodermal dystrophy patients. Human Genetics 1998103 428-434.

12 Wang CY, Davoodi-Semiromi A, Huang W, Connor E, Shi JD \& She JX. Characterization of mutations in patients with autoimmune polyglandular type I (APS1). Human Genetics 1998103 681-685.

13 Heino M, Scott HS, Chen Q, Peterson P, Maebpaa U, Papasavvas MP et al. Mutation analyses of North American APS-1 patients. Human Mutation 199913 69-74.

14 Ward L, Paquette J, Seidman E, Huot C, Alvarez F, Crock P et al. Severe autoimmune polyendocrinopathy-candidiasis-ectodermal dystrophy in an adolescent girl with a novel AIRE mutation: response to immunosuppressive therapy. Journal of Clinical Endocrinology and Metabolism $1999 \mathbf{8 4} 844-852$.

15 Björses P, Halonen M, Palvimo JJ, Kolmer M, Aaltonen J, Ellonen P et al. Mutations in the AIRE gene: effects on subcellular location and transactivation function of the autoimmune polyendocrinopathy-candidiasis-ectodermal dystrophy protein. American Journal of Human Genetics 200066 378-392.

16 Gibson TJ, Ramu C, Gemünd C \& Aasland R. The APECED polyglandular autoimmune syndrome protein, AIRE-1, contains the SAND domain and is probably a transcription factor. Trends in Biochemical Sciences 199823 242-244.

17 Heino M, Peterson P, Kudoh J, Nagamine K, Lagerstedt A, Ovod V et al. Autoimmune regulator is expressed in the cells regulating immune tolerance in thymus medulla. Biochemical and Biophysical Research Communications 1999257 821-825.

18 Björses P, Pelto-Huikko M, Kaukonen J, Aaltonen J, Peltonen L \& Ulmanen I. Localization of APECED protein in distinct nuclear structures. Human Molecular Genetics 19998 259-266.

19 Rinderle C, Christensen HM, Schweiger S, Lehrach H \& Yaspo ML. AIRE encodes a nuclear protein co-localizing with cytoskeletal filaments: altered sub-cellular distribution of mutants lacking the PHD zinc fingers. Human Molecular Genetics 19998 277-290.

20 Gibbons RJ, Bachoo S, Picketts DJ, Aftimos S, Asenbauer B, Bergoffen $\mathrm{J}$ et al. Mutations in transcriptional regulator ATRX establish the functional significance of a PHD-like domain. Nature Genetics 199717 146-148.

21 Thenot S, Henriquet C, Rochefort H \& Cavailles V. Differential interaction of nuclear receptors with the putative human transcriptional coactivator hTIF1. Journal of Biological Chemistry $199727212062-12068$.

22 Kim SS, Chen YM, O'Leary E, Witzgall R, Vidal M \& Bonventre JV. A novel member of the RING finger family, KRIP-1, associates with the KRAB-A transcriptional repressor domain of zinc finger proteins. PNAS 199619 15299-15304.

23 Ge Q, Nilasena DS, O'Brien CA, Frank MB \& Targoff IN. Molecular analysis of a major antigenic region of the $240-\mathrm{kD}$ protein of Mi-2 autoantigen. Journal of Clinical Investigation 1995 96 1730-1737.

24 Zhang Y, LeRoy G, Seelig HP, Lane WS \& Reinberg D. The dermatomyositis-specific autoantigen $\mathrm{Mi} 2$ is a component of a complex containing histone deacetylase and nucleosome remodeling activities. Cell 199895 279-289.

25 Kim J, Sif S, Jones B, Jackson A, Koipally J, Heller E et al. Ikaros DNA-binding proteins direct formation of chromatin remodeling complexes in lymphocytes. Immunity 199910 345-355.

26 Wade PA, Gegonne A, Jones PL, Ballestar E, Aubry F \& Wolffe AP. Mi-2 complex couples DNA methylation to chromatin remodelling and histone deacetylation. Nature Genetics 199923 62-66.

Received 8 September 2000

Accepted 12 December 2000 